\title{
What are the fundamental meanings of money?
}

\author{
Minh-Hoang Nguyen \\ Centre for Interdisciplinary Social Research \\ Phenikaa University \\ Yen Nghia, Ha Dong, Hanoi 100803, Vietnam
}

October 19, 2021
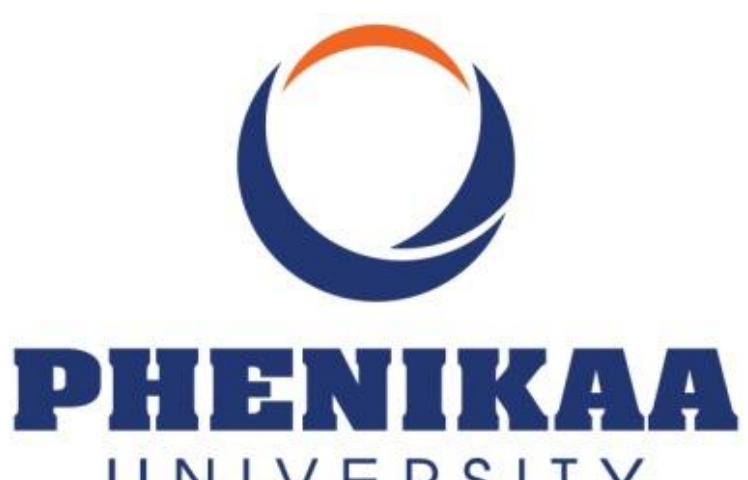

UNIVER S I T Y

$* * * * * * * *$

A few days ago, I had a conversation with my mentor about the economic structures of humankind. One question popped up in my mind:

\section{What are the fundamental meanings of money?}

After reflecting on my observations and experience, I think that money has two fundamental meanings:

- $\quad$ Pursuing perceived freedom

- Enhancing perceived impact

To know why let's talk about what money is and what we can do with money first.

Money, by definition, is a medium of exchange that allows us to trade with other people and obtain what we want or need [1]. In a deeper sense, money is a unit of account that is socially accepted to have a certain value. For example, thousands of years ago, shells and beads appeared to be mediums that people used to exchange useful commodities. However, everything has changed. If shells and beads were still used as mediums of exchange instead of US dollars and gold at the moment, countries near the coastline, like Vietnam (my country), would have been one of the richest nations on the planet. What 
makes the medium of exchange different between now and then is the social belief in the medium's value.

\section{So, what is value? How can we know that an object has a value(s)?}

According to the Oxford dictionary, value has myriad meanings, both countable and uncountable, such as how much something is worth in money, how much other goods for which it can be exchanged, the quality of being useful or important, or beliefs about what is right or wrong. In any case, value demonstrates the perceived impact of a particular thing on other things, so it is subjectively driven. To elaborate, two people with different mindsets and facing different situations will consider a similar thing with distinct values. For instance, a billionaire will not mind losing a couple of dollars on the street, while that money can be a whole fortune for a homeless person. Or, a person owning gasoline will consider a car valuable for travelling, but a person without gasoline will consider it useless.

Now, we know that money is a medium of exchange that is widely accepted by a group of people (a society or, on a smaller scale, an institution), and its perceived value is dissimilar among people. This might sound paradoxical, right?

The paradox happens because the socially accepted value is objective, while the perceived value is subjectively driven by an individual's mindset and observed information. The objective fact can influence the subjective value assessment of an individual, but it will be distorted by the individual's multi-filtering system (mindset, memory, and perceived information from the surrounding environment) [2-4]. For example, one US dollar today (October 14 2021) is socially accepted to be exchanged for around 22 thousand VND because it is an official exchange rate announced by Vietnamese banks. However, when the surrounding environment (or context) is changed, like at the black market, people will agree to exchange 25 thousand VND for one US dollar because there is no exchange cap in the black market, and they can exchange more than 10 thousand US dollars. In case a person has no prior expectation of exchange value, for example, a kid, he/she will agree to exchange one US dollar for an ice cream worth 8 thousand VNĐ. Based on this way of thinking, I assert that the value of one unit of money is subjectively different among people, although it has a socially accepted value.

\section{What is money used for?}

To the best of my knowledge, there are only two ways to interact with money, regardless of its perceived value. The first way is that we accumulate or earn them. Another way is to spend them. In other words, money is for "take and give". It should be noted that I only consider socially accepted mediums of exchange as money (e.g., US dollar, VNĐ, gold), but not those that used to be (e.g., shells and beads).

\section{But, where do we take it from and give it to?}


In real life, there are two natural rules that all of us follow. First, human beings have limited physical and mental capacities (e.g. strength, health, intelligence, stress tolerance) and time. Second, there are many needs that human beings must or want to meet. These needs range from physiological (e.g. food, shelter, air) to self-actualization needs (e.g. self-development, self-advancement). Due to these rules, humans have to behave so that they can meet their needs without exceeding the capacity of a human being. Otherwise, physical or mental breakdowns will happen and lead them to become "non-existent" (e.g. health loss, mental illness). In other words, human beings capitalize their physical and mental capabilities and time to earn money, then use the money to exchange for other goods and services provided by other people.

Let's take an example. A man has many needs that have to be met, like eating a hamburger, drinking a coke, travelling from Hanoi to Ho Chi Minh city, playing video games, etc. Nevertheless, everyone only possesses 24 hours, a certain amount of stamina and mental power in a day, so does the man. Due to physical and time constraints, it is impossible for him to walk from Hanoi to Ho Chi Minh city or create a computer by himself for entertainment. All of these goods and services have to be provided by other people specialized for making food, flying a plane, or manufacturing computers.

\section{Subjective spheres of influence: A perceptual system beyond Mindsponge}

To further explain the fundamental meanings of money, I developed a framework regarding an individual's subjective spheres of influence based on the assumptions made above and the Mindsponge mechanism [5-7] to illustrate how individuals perceive what they can influence and what can influence them. 

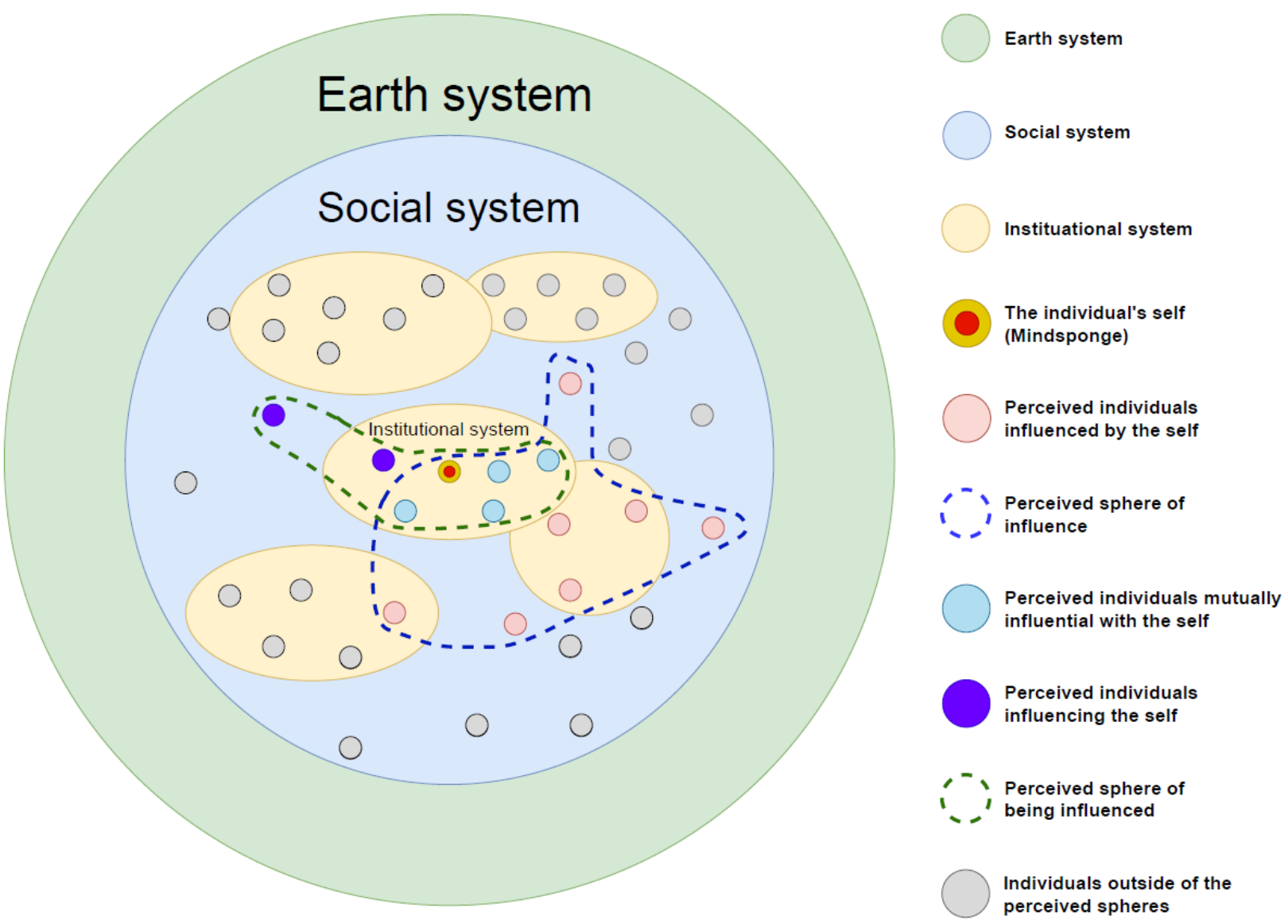

Figure 1: The subjective spheres of influence

As humans, we live and are attached to multiple systems that might cover or intertwine with the other. Figure 1 illustrates my imagination about the system, with the Earth system being the largest system, represented by the green area. Within the Earth system, there are many social systems that represent different societies with distinct socio-cultural constructs. In the Figure, I only focus on one social system, represented by the blue area (readers can view it as a social system within a country for interpretation), because money is only accepted within a society. The sub-sets of a social system are various institutional systems, represented by yellow areas. Such institutions are founded by a group of people for a certain purpose, like university, enterprise, government, etc.

As for people, there are five types of people:

1) The self (yellow and red bubble)

2) The individuals perceived to be mutually influential with the self (cyan bubbles)

3) The individuals perceived to be influenced by the self (light red bubbles)

4) The individuals perceived to be able to influence the self (purple bubbles) 
5) The individuals perceived to have no interaction with the self (grey bubbles)

Two spheres determine these five types of people: 1) the perceived sphere of influence and 2) the perceived sphere of being influenced. I assume that any individual has an abstract or clear boundary of their sphere of influence (blue dash line) and sphere of being influenced (green dash line). In other words, they have a certain perception about whom they can influence and whom they cannot, and perception about who can influence them and who cannot influence them. The influence here can be interpreted in many ways, including but not limited to physical influences (e.g., materials, money, behaviors), mental influences (e.g., prestige, personality, emotion).

\section{Money as a medium of influential power}

Following this way of thinking, money can be seen as one of many mediums of influential power between the self and other people, of which the weight is determined by the subjective judgement of the individual on the money's value. For acquiring demanded goods and services, a self can use the influential power of money to purchase. In other words, this is an influencing process in which the self uses a certain amount of money to influence other people to provide them with goods and services. However, money does suddenly appear from the void. The self can only acquire it by using their physical and mental capabilities and time to create certain goods or services for other people. This is the process in which other people influence an individual through payments. It should be noted that the processes that an individual can influence and be influenced using money can only occur among human beings, but neither animals nor physical objects.

Regardless of the weight, large or small portion, the money can always be accumulated. The more money the self accumulates, the more influential power they can own. Eventually, such power can be used to influence other people to provide the self with goods and services they demand. Given this fact, a wealthy self might perceive itself as more influential to other people than a poor self. In contrast, a poor self might perceive itself as dependent on other people than the wealthy self. However, when money is accumulated to a certain level, it might give the self the power (or choice) to get rid of such a perception of financial dependence. In other words, the self might perceive that the influential power of other people on them will decline when it becomes richer. Is this not a type of freedom?

Nevertheless, as the perceived value is subjectively driven by the self's mindset and observed information, the influential power of money is not always similar to the influential power that is widely accepted in society. Also due to this subjectivity, the perceived influential power of a unit of money is different depending on the target, the self's preferences, and context.

Until here, I advocate that money has two fundamental meanings: 1) pursuing perceived freedom and 2) enhancing perceived impact. The arguments that lead to this conclusion 
might be still weak, but the conceptual development of the subjective sphere of influence framework is valuable. The influence in the framework should not be solely interpreted as money but also as other matters, like physical influences (e.g., materials, money, behaviors), mental influences (e.g., prestige, personality, emotion). This framework is expected to help explain the multiplexity of political, economic, social-cultural issues across disciplines. One of the potential hypotheses derived from this framework is that individuals will think and behave differently towards targets belonging to different perceived spheres of influence and being influenced.

\section{References}

1. Chính PM, Hoàng VQ. (2021). Kinh tế Việt Nam: Thăng trầm và đột phá. Nxb Chính trị Quốc gia, Hà Nội.

2. Nguyen MH, Le TT, Nguyen HKT, Ho MT, Nguyen HTT, Vuong QH. (2021). Alice in Suicideland: Exploring the suicidal ideation mechanism through the sense of connectedness and help-seeking behaviors. International Journal of Environmental Research and Public Health, 18(7), 3681. https://doi.org/10.3390/ijerph18073681

3. Vuong QH, Nguyen MH, Le TT. (2021). A mindsponge-based investigation into the psycho-religious mechanism behind suicide attacks. Warsaw, Poland: De Gruyter.

4. Vuong QH, Nguyen MH, Le TT. (2021). Home scholarly culture, book selection reason, and academic performance: Pathways to book reading interest among secondary school students. European Journal of Investigation in Health, Psychology and Education, 11(2), 468-495. https://doi.org/10.3390/ejihpe11020034

5. Nguyen MH, Vuong QH, Ho MT, Le TT. (2021). Mindsponge Mechanism. Scholarly Community Encyclopedia. Retrieved from https://encyclopedia.pub/7320

6. Vuong QH. (2016). Global mindset as the integration of emerging socio-cultural values through mindsponge processes: A transition economy perspective. In J. Kuada (Ed.), Global Mindsets: Exploration and Perspectives (pp. 123-140). New York: Routledge.

7. Vuong QH, Napier NK. (2015). Acculturation and global mindsponge: An emerging market perspective. International Journal of Intercultural Relations, 49, 354-367. https://doi.org/10.1016/j.ijintrel.2015.06.003 